\title{
International Federation for Emergency Medicine Consensus Statement: Sonography in hypotension and cardiac arrest (SHoC): An international consensus on the use of point of care ultrasound for undifferentiated hypotension and during cardiac arrest - CORRIGENDUM
}

P. Atkinson; J. Bowra; J. Milne; D. Lewis; M. Lambert; B. Jarman; V. E. Noble; H. Lamprecht; T. Harris; J. Connolly

And members of the International Federation of Emergency Medicine Sonography in Hypotension and Cardiac Arrest working group: R. Gaspari; R. Kessler; C. Raio; P. Sierzenski; b. Hoffmann; C. Pham; M. Woo; P. Olszynski; R. Henneberry; O. Frenkel; J. Chenkin; G. Hall; L. Rang; M. Valois; C. Wurster; M. Tutschka; R. Arntfield; J. Fischer; M. Tessaro; J.S. Bomann; A. Goudie; G. Blecher; A. Salter; M. Rose; A. Bystrzycki; S. Dass; O. Doran; R. Large; H. Poncia; A. Murray; J. Sadewasser; R. Breitkreutz; H. C. Toh; A. A. Cevik; A. S. Hu; L. Melniker

doi:10.1017/cem.2016.394

In the original publication of "International Federation for Emergency Medicine Consensus Statement: Sonography in hypotension and cardiac arrest (SHoC): An international consensus on the use of point of care ultrasound for undifferentiated hypotension and during cardiac arrest," five authors were not listed in the IFEM $\mathrm{SHoC}$ group, both in the author listing and in the Acknowledgments section. They are as follows:

Raoul Breitkreutz, MD; Hong Chuen Toh, MB; Arif Alper Cevik, MD; Ang Shiang $\mathrm{Hu}, \mathrm{MB}$; and Larry Melniker, MD, MS.
The authors and editors regret these omissions, and the original article has since been updated.

\section{REFERENCE}

Atkinson P, Bowra J, Milne J, et al. International Federation for Emergency Medicine Consensus Statement: Sonography in hypotension and cardiac arrest (SHoC): An international consensus on the use of point of care ultrasound for undifferentiated hypotension and during cardiac arrest. CFEM 2016; epub, doi:10.1017/cem.2016.394. 